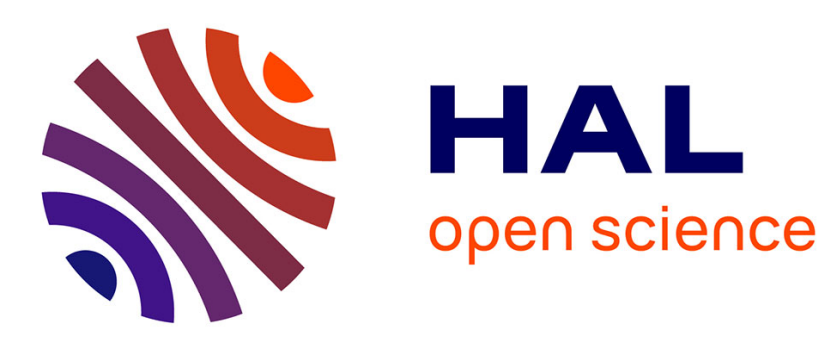

\title{
Stress wave induced damage and fracture in impacted glasses
}

\author{
H. Senf, E. Strassburger, H. Rothenhäusler
}

\section{To cite this version:}

H. Senf, E. Strassburger, H. Rothenhäusler. Stress wave induced damage and fracture in impacted glasses. Journal de Physique IV Proceedings, 1994, 04 (C8), pp.C8-741-C8-746. 10.1051/jp4:19948114 . jpa-00253356

\section{HAL Id: jpa-00253356 https://hal.science/jpa-00253356}

Submitted on 1 Jan 1994

HAL is a multi-disciplinary open access archive for the deposit and dissemination of scientific research documents, whether they are published or not. The documents may come from teaching and research institutions in France or abroad, or from public or private research centers.
L'archive ouverte pluridisciplinaire HAL, est destinée au dépôt et à la diffusion de documents scientifiques de niveau recherche, publiés ou non, émanant des établissements d'enseignement et de recherche français ou étrangers, des laboratoires publics ou privés. 


\title{
Stress wave induced damage and fracture in impacted glasses
}

\author{
H. Senf, E. Strassburger and H. Rothenhäusler \\ Fraunhofer-Institut für Kurzzeitdynamik, Ernst-Mach-Institut, Postfach 12 70, 79547 Weil am Rhein, \\ Germany
}

\begin{abstract}
The conditions for crack nucleation under impact loading were investigated systematically for four glasses which differ in their chemical composition, hardness and material density. Edge-on impact experiments were carried out with blunt steel cylinders within the velocity range from $20 \mathrm{~m} / \mathrm{s}$ to $1000 \mathrm{~m} / \mathrm{s}$. The propagation of shock waves, of primary and secondary cracks and crack systems and the growing of crack systems from nucleated centers were observed by means of a Cranz-Schardin camera in a shadow optical arrangement.
\end{abstract}

Résumé - Les conditions pour la nucleation de fissures due a une charge d'impact ont été étudiées systématiquement pour quatre sortes de verre qui se distingnent par leur composition chimique, leur dureté et leur densité du matériau. Des essais avec impact sur les bords furent réalisés avec des cylindres d'acier émoussé dans la gamme de vitesse de $20 \mathrm{~m} / \mathrm{s}$ à $1000 \mathrm{~m} / \mathrm{s}$. Nous avons observé à l'aide d'une caméra Cranz-Schardin, qui faisait partie d'un système optique ombroscopique, la propagation d'ondes de choc, de fissures et de systèmes de fissures primaires et secondaires et le développement de systèmes de fissures à partir de centres de nucléation.

\section{INTRODUCTION}

The damage processes in glass targets at high impact loadings are investigated in order to get deeper and more fundamental knowledge on the terminal ballistic resistance of laminated targets with metallic plates and non-metallic brittle materials as intermediate layers $[1,2,3]$. In this connection the questions arise, how the non-metallic components are destroyed or comminuted by fracture processes and how the interaction between the fragments themselves or the interaction with the confining metallic cover plates influences the penetration or perforation processes. This paper focuses on the analysis of different types of damage and their connection with stress waves. The answers to these questions are of importance with respect to the further development of models that describe brittle fracture and penetration processes.

\section{EXPERIMENTAL SET-UP}

Figure 1 shows the experimental set-up for investigating the propagation of waves and damage in glass schematically. The kinematics of the processes in the target plate were directly photographed using a Cranz-Schardin multiple spark high speed camera. The projectiles were accelerated by gas and powder guns and hit the edge of the specimen. The impact velocity was varied in the range from $v_{P}=1000 \mathrm{~m} / \mathrm{s}$ down to $20 \mathrm{~m} / \mathrm{s}$ for blunt steel cylinders (diameter $30 \mathrm{~mm}$ and length $23 \mathrm{~mm}$ ).

The target plates of optical glass used in the experiments had the lateral dimension $100 \mathrm{~mm} \times 100 \mathrm{~mm}$, the dimension of the float glass specimen ranged from $100 \mathrm{~mm} \times 100 \mathrm{~mm}$ to $180 \mathrm{~mm} \times 180 \mathrm{~mm}$. The thickness of all the glass targets was $10 \mathrm{~mm}$. 


\section{TYPES OF GLASS TARGETS}

Float glass and three optical glasses (K5, F6, and SF6) from SCHOTT Company were used for target material. The physical properties of the different types of glasses are listed in Table 1 . The sound wave velocity $c_{T}$ in float glass was measured by Kerkhof [4]. The wave velocities of the optical glasses were calculated taking the SCHOTT data (material density $\rho$, the E-Modulus and the Poisson ratio $v$ ).

Table 1. Physical properties

\begin{tabular}{|c|c|c|c|c|c|}
\hline Type & $\begin{array}{c}\text { Density } \\
{\left[\mathrm{g} / \mathrm{cm}^{3}\right]}\end{array}$ & $\begin{array}{c}\text { E-Modulus } \\
{\left[10^{3} \mathrm{~N} / \mathrm{mm}^{2}\right]}\end{array}$ & $\begin{array}{c}\text { Poisson } \\
\text { ratio }\end{array}$ & HV & $\begin{array}{c}\text { Sound speed } \\
{[\mathrm{m} / \mathrm{s}]}\end{array}$ \\
\hline Float & 2.5 & -- & -- & 680 & 5860 \\
K5 & 2.59 & 71 & 0.227 & 584 & 5624 \\
F6 & 3.76 & 57 & 0.231 & 455 & 4196 \\
SF6 & 5.18 & 56 & 0.248 & 407 & 3595 \\
\hline
\end{tabular}

\section{DAMAGE PHENOMENOLOGY}

Differing types of damage in glass plates have to be distinguished which occur during edge-on impacts with blunt projectiles. In this paper the different phenomena are presented by one characteristic picture only that belongs to a series of 20 pictures.

After impact a high number of single cracks grow from the area of impact (Fig. 2). These cracks are called radial cracks and the front of their tips the primary crack front. The planes of the single cracks are normally orientated to the plane of the glass plate.

A further type of cracks propagates with its surface parallel to the surface plane of the specimen. This kind of cracks approaches the surface of the target plate with increasing distance from the impacted edge and cleave the plates into shell-shaped or wedge-shaped slices. Figure $2 a$ shows a schematic representation of these types of cracks. On the photograph (Fig. 2b) the front of the shell-shaped crack appears as a black semicircular line along the tips of the radial cracks. This means, both crack systems were initiated simultaneously and they propagated with the same velocity.

It was also observed that the primary cracks form a planar front, i. e., cracks have been generated simultaneously on the whole contact area between projectile and target (Fig. 3, float glass, impact velocity 48 $\mathrm{m} / \mathrm{s})$.

Additionally, Figure 3 shows cracks which were generated at the edge of the glass plate above and below the projectile. The spaces between these cracks are irregular. The cracks start from the edge of specimen in a direction normal to it and then change their direction of propagation so that an angle of about $30^{\circ}$ is included between the cracks and the shot line. All these cracks grow with constant velocity $v_{C}$ and will be denoted secondary cracks in the following. The secondary cracks are initiated successively by the shear wave which is generated at the edge of the projectile. Therefore, the secondary crack system exhibits a triangular shape.

A further damage mechanism is observed (Fig. 4). Crack centres are initiated between the first compressive wave front and the primary crack front. The inhomogeneities in the loaded material turn into the initial points or nucleation points of cracks which spread in all directions. It is these cracks and not the nucleation points or nuclei that are visualised by the high-speed photographs, but to simplify discussions the designations "crack centre" and "nucleus" are used synonymously. In the first stage of development the centers are shaped like ellipsoids whose major axis is directed towards the impact centre.

At high impact velocities $(220 \mathrm{~m} / \mathrm{s})$ no details can be recognized in the impact zone. Only a black area is seen in front of the projectile. The light is deflected by the primary crack and shell-shaped fracture systems and the crack centers and the stress waves in this zone.

\section{THE DAMAGE VELOCITY CONCEPT}

The concept of damage velocity is introduced to describe the different damage processes quantitatively. The path-time curves of the primary crack front and of the cracks, which start from the nuclei in and against the direction of the shock wave, are determined. At the high dynamic loadings considered in these investigations all cracks propagate with constant velocity $\mathrm{v}_{C}$, which has turned out to be a characteristic quantity for each type of glass in previous investigations $[1,4,5,6,7]$ and is called terminal velocity $v_{C}$. 
Therefore, the path-time curves are all straight lines. The intersection points of those straight lines, which describe the cracks starting from the nucleation points, determine the places " $\mathrm{s}$ " and times " $\mathrm{t}$ " of nucleation. The slope of the line through the nucleation points $(s, t)$ is defined as the damage velocity $v_{D}$. Figure 5 shows the evaluation of the experiment shown in Figure 3 (only one representative picture from a series of 20 pictures). The filled triangles determine the progress of the tips of the secondary crack systems above the projectile. The blank triangles and squares represent the fore and rear front of the nucleated crack systems. One recognises, that the first point of nucleation is localised on the line, which describes the lateral spread of the secondary crack region. That means, in this case the damage velocity $v_{D}$ equals the velocity of the lateral initiation of the secondary cracks: $v_{D}=v_{S R}=3030 \mathrm{~m} / \mathrm{s}$.

\section{DAMAGE VELOCITIES AND THRESHOLDS FOR NUCLEATION}

Recent investigations $[3,5,6]$ showed that the damage velocities could be related to the energy which is transferred to the target by the shock wave. This energy density or specific energy $E$ (energy per unit volume) is determined by the acoustic impedances of the target and the projectile materials and the impact velocity $v_{p}$. Multiplication of $E$ by the area of contact $A$ between projectile and target results in a quantity of the unit [Newton]. Therefore, E.A is interpreted as a momentum flux. Figure 6 shows the damage velocities $v_{D}$ for the four glasses versus the momentum flux $E \cdot A$. The experimental curves show similar courses for all types of glasses. At low loadings the specimens are destroyed by the primary and secondary cracks which start at the impacted edge. In this case the damage velocity $\mathrm{v}_{\mathrm{D}}$ equals the maximum or terminal crack velocity $v_{C}$ of the type of glass considered (Table 2 ). The damage velocity rises to the order of magnitude of the transversal wave velocity $c_{T}$ when nucleation occurs. At first, a further increase of the loading leads to a slow increase of $v_{D}$. With very high loadings this velocity approaches the longitudinal wave velocity $\mathrm{c}_{\mathrm{L}}$ asymptotically. In the loading range, where $\mathrm{v}_{\mathrm{D}}$ increases slowly, an increase of the number of initiated nuclei is observed. It is remarkable that the thresholds where nucleation occurs with differing glasses do not differ significantly from one another in spite of the great differences in the physical properties. The experimental results for the optical glass K5 and float glass are represented by one curve only because it was not possible to make a distinction from the values measured. Table 2 shows a list of the lowest impact velocities $v_{p}$ and the corresponding initial intensities $p$ of the pressure waves where nucleation was stimulated.

Table 2. Terminal crack velocities (mean value $\mathrm{v}_{\mathrm{C}}$ and standard deviation), impact velocity $\mathrm{v}_{\mathrm{PNucl}}$ and initial pressure $\mathrm{p}$, when nucleation occurs

\begin{tabular}{|c|c|c|c|}
\hline Material & $\mathrm{v}_{\mathrm{C}}[\mathrm{m} / \mathrm{s}]$ & $\mathrm{v}_{\mathrm{PNucl}}[\mathrm{m} / \mathrm{s}]$ & $\mathrm{p}[\mathrm{MPa}]$ \\
\hline Float glass & $1550 \pm 31$ & 34 & 379 \\
K5 & $1550 \pm 23$ & 35 & 388 \\
F6 & $1100 \pm 54$ & 25 & 294 \\
SF6 & $700 \pm 48$ & 21 & 278 \\
\hline
\end{tabular}

\section{DISCUSSION OF THE RESULTS}

The observed crack and damage velocities, beginning from the level of the terminal crack velocity up to the transversal wave velocity and the asymptotic approach of longitudinal wave velocity $c_{L}$ correspond to the following types of damages. All the experiments showed, that cracks first start from the impacted edge of the specimen above and below the border of projectile (secondary crack systems). The formation of the primary cracks begins later than the formation of the secondary cracks (see Fig. 3). Shear waves are generated at the border of the projectile and a compressive wave ahead of the contact area. The experiments show that cracks are generated first under the influence of shear loading at the edge of the target plates.

The crack generation caused by nucleation shows similar behaviour. That means, nucleation is initiated when the intensity of the shear wave exceeds a certain level. The loading range, where on the one hand the amplitude of the transversal wave is high enough to stimulate all the potential nuclei, but on the other hand the intensity of the compressive wave is not sufficiently high to nucleate cracks, corresponds to the plateau in the $v_{D}$-E.A-diagram with $v_{D}=c_{T}$. Only these crack centers are considered which are generated before the release waves from the edges of the specimen have arrived at their position. 
At higher loading rates the nucleation is already observed within the range which has only passed by the compressive wave. Figure 7 a shows an example of this case, where the projectile hit the SF6-target at $v_{P}$ $=450 \mathrm{~m} / \mathrm{s}$. The photograph shows the nuclei immediately behind the second compressive wave front.

The formation of the second wave front is caused by the finite thickness of the target plate [5]. The pathtime curve of this experiment (Fig. 7b) shows that the points of nucleation are placed between the straight lines which represent the pressure wave and the shear wave, i. e., the compressive wave triggers the crack formation at the points of nucleation. This explains the damage propagation with approximately sound velocity at high loading rates.

\section{ACKNOWLEDGEMENT}

We are thankful for the encouragement by William A. Gooch to perform this work and for the financial support by the U. S. Army Research Laboratory, Aberdeen Proving Ground, Maryland, through the European Research Office of the U.S. Army, London, UK. The experiments were carried out very carefully by Dieter Preuss, Joerg Gonschorek and Edgar Zipfel.

\section{REFERENCES}

[1] U. Hornemann, H. Rothenhäusler, H. Senf, J.F. Kalthoff, S. Winkler: "Experimental investigation of wave and fracture propagation in glass slabs loaded by steel cylinders at high impact velocities", Inst. Phys. Conf. Ser. No. 70, 3rd Conf. Mech. Prop. High Rates of Strain, Oxford, 1984

[2] H. Senf, H. Rothenhäusler, W. Pavel, H.-J. Raatschen, R. Schwarz: "Analysis of experimental and numerical investigations with rigid projectiles impacting glass targets of differing physical quality", Journal de Physique, Colloque C3, Suppl. au no 9, Tome 49, 1988

[3] H. Senf, H. Rothenhäusler, "Crack behaviour and dynamic response of alumina under impact loading", Shock-Wave and High-Strain-Rate Phenomena in Materials, Marc A. Meyers, Lawrence E. Murr, Karl P. Staudhammer, MARCEL DEKKER, Inc., 1992

[4] F. Kerkhof, "Bruchvorgänge in Glas", Verlag der Deutschen Glastechnischen Gesellschaft, Frankfurt/Main, 1970

[5] E. Straßburger, H. Senf, H. Rothenhäusler, "Stoßwelleninduzierte Risse und Zerstörungen in Gläsern", Fraunhofer-Institut für Kurzzeitdynamik, Weil am Rhein, EMI-Report 7/93, 1993

[6] S. Winkler, H. Senf, H. Rothenhäusler, "Wave and fracture phenomena in impacted ceramics", Fraunhofer-Institut für Kurzzeitdynamik, Weil am Rhein, EMI-Report V 5/89, 1989

[7] H. Schardin, "Results of kinematographic investigation of the fracture process in glass", Technical Memorandum, Navy-NOTS TM 968, U. S. Naval Ordnance Test Station, China Lake, California, USA, p. 29, 1953

"For reasons of space, only References to the research of the EMI are given"

\section{FIGURES}

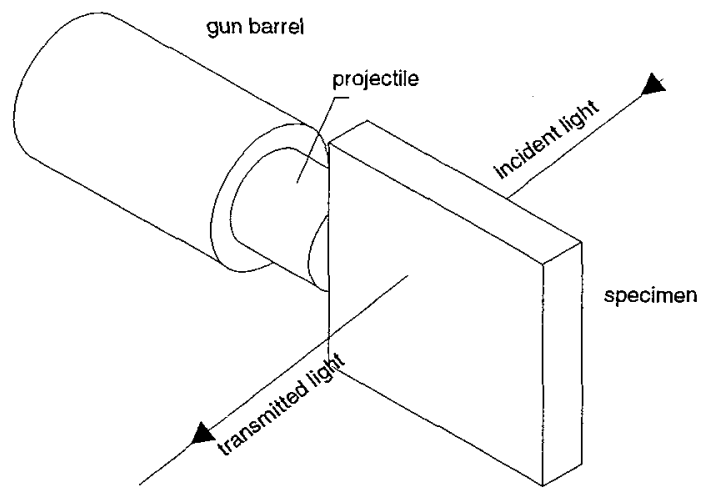

Fig. 1. Schematic of the experimental arrangement 

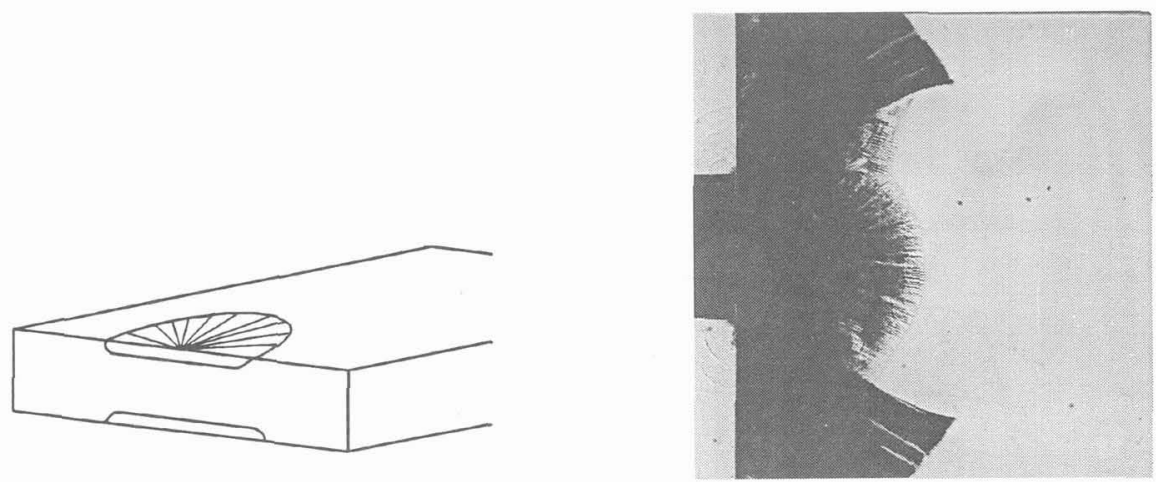

Fig. 2. a) Shell-shaped crack systems with radiating cracks; a) schematics, b) photograph (float glass; $30.5 \mu \mathrm{s}$ after impact; impact velocity $v_{P}=77 \mathrm{~m} / \mathrm{s}$ ); \# 10019

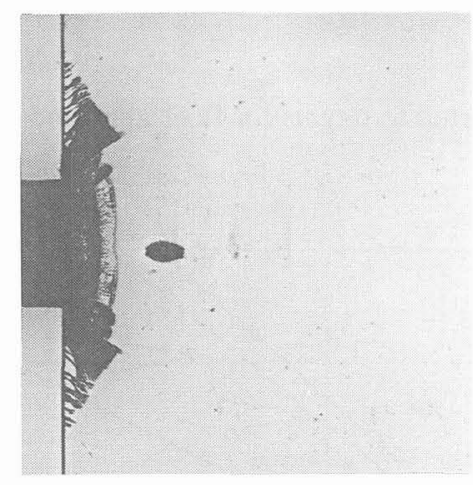

Figure 3

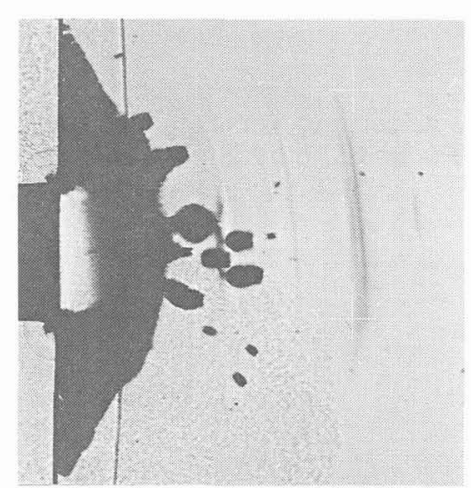

Figure 4

Fig. 3. Planar propagation of primary and shell-shaped crack fronts (float glass; projectile speed $\mathbf{v}_{\mathrm{P}}=$ $48 \mathrm{~m} / \mathrm{s} ; \mathrm{t}=10.7 \mu \mathrm{s}$ after impact; \# 10286)

Fig. 4. Damage development in float glass at impact velocity $v_{p}=220 \mathrm{~m} / \mathrm{s} ; \mathrm{t}=13 \mu \mathrm{s} ; \# 10013$

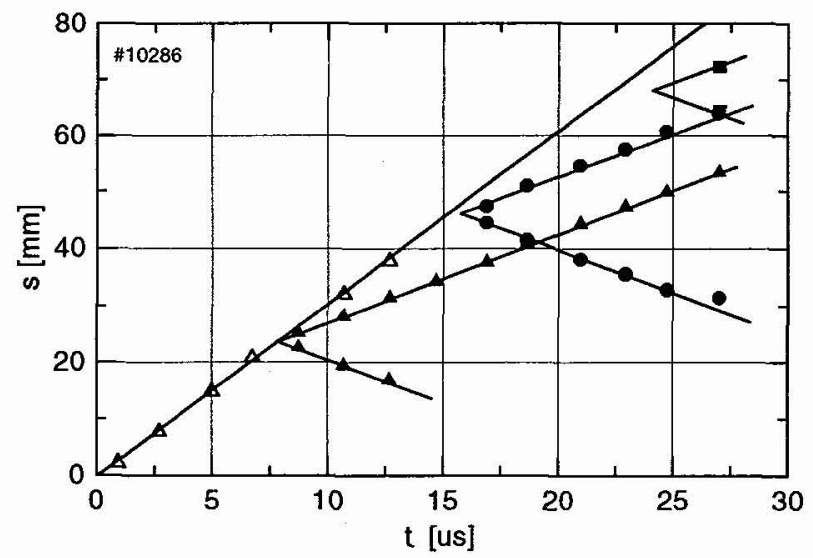

Fig. 5. Path-time history of damages, \# 10286 (see photograph Fig. 3) 


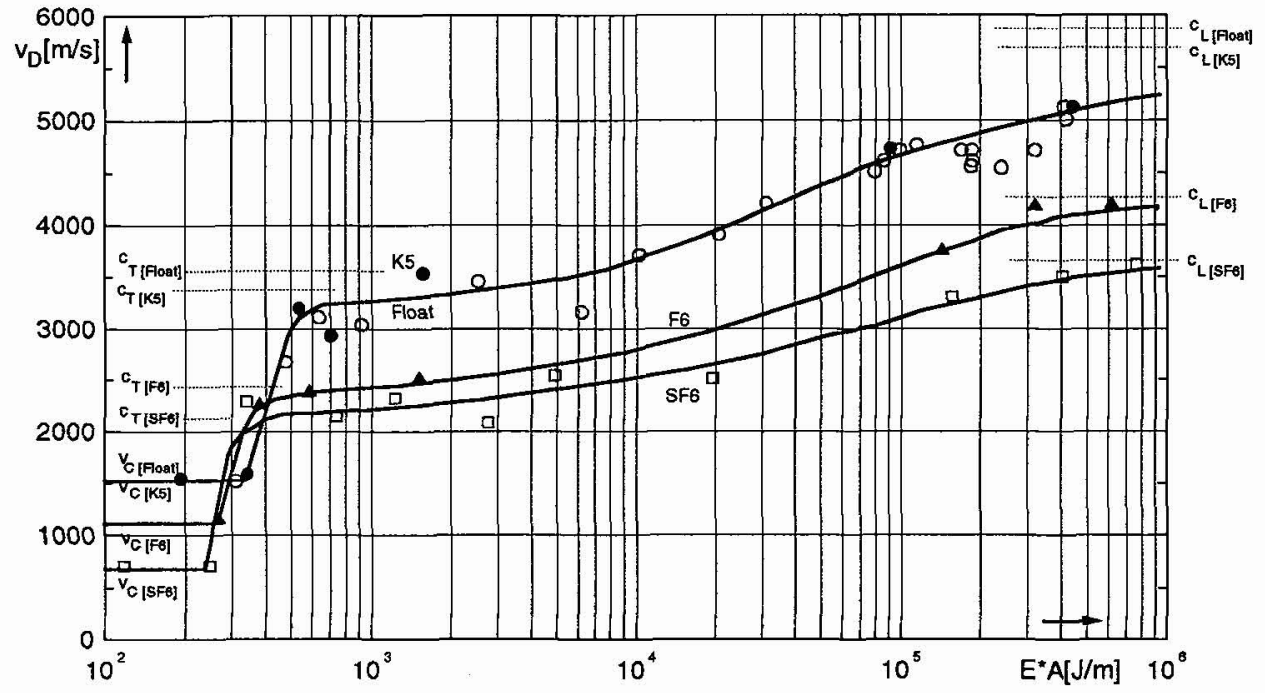

Fig. 6. Damage velocity $v_{D}$ versus momentum flux $E \cdot A$ transferred to targets for float glass and the optical glasses $\mathrm{K5}, \mathrm{F} 6$, and $\mathrm{SF} 6$ by impact
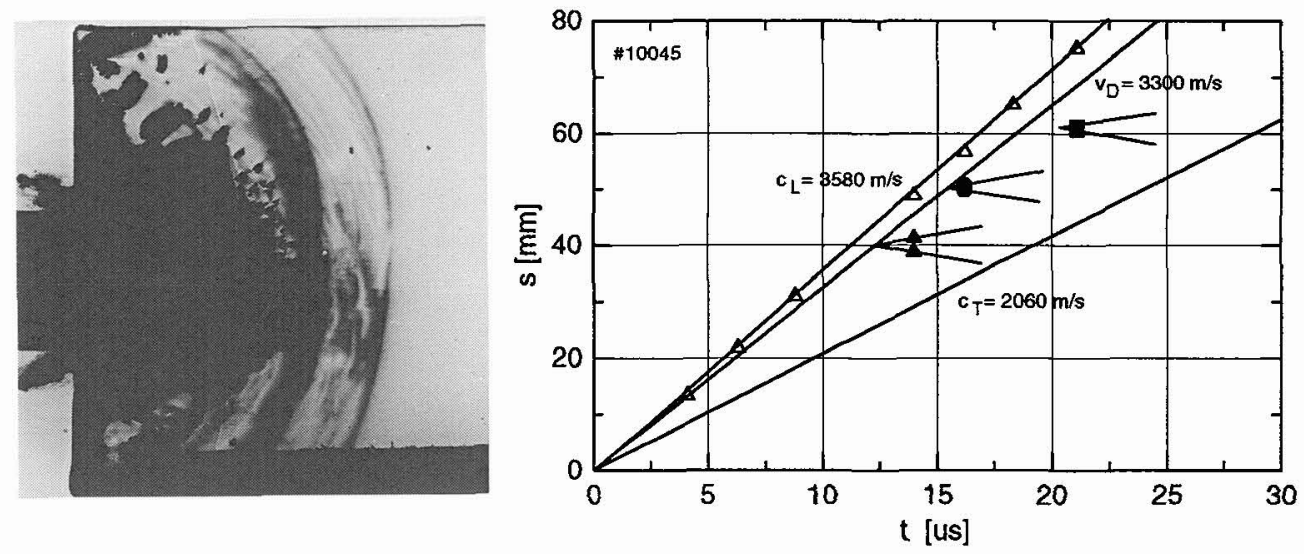

Fig. 7. a) Damage in SF6 glass $21.9 \mu$ s after impact, $v_{P}=450 \mathrm{~m} / \mathrm{s}$; b) Path-time history of \# 10045 